PII: S0735-1933(03)00156-8

\title{
THE IMPACT OF THERMALLY SIGNIFICANT BLOOD VESSELS IN PERFUSED TUMOR TISSUE ON THERMAL DOSE DISTRIBUTIONS DURING THERMAL THERAPIES
}

\author{
Tzu-Ching Shih ${ }^{(1)}$, Hong-Sen Kou ${ }^{(1)}$, and Win-Li Lin ${ }^{(2)}$ \\ Department of Mechanical Engineering, Tatung University ${ }^{(1)}$ \\ Institute of Biomedical Engineering, National Taiwan University ${ }^{(2)}$ \\ Taipei, Taiwan, Republic of China \\ (E-mail: hskou@ttu.edu.tw)
}

(Communicated by J.P. Hartnett and W.J. Minkowycz)

\begin{abstract}
This study demonstrates the effects of thermally significant blood vessels on thermal lesion sizes during thermal therapies. The thermal model combines the Pennes [1] bio-heat transfer describing for perfused tissue and the energy equation for blood vessel. A finite difference method was used to solve the transient equation of heat transfer in perfused tumor tissue with a blood vessel in cylindrical coordinates. The thermal dose distribution was determined by the formulation proposed by Sapareto and Dewey [2]. Simulation results quantitatively show that the blood vessel diameter and the averaged blood velocity are the crucial factors determining the thermal dose distribution near the blood vessel for thermal therapies. When a blood vessel diameter passing throughout the heated volume is larger than $1 \mathrm{~mm}$, the thermal dose level may become too low and then lose its hyperthermia effect. @ 2003 Elsevier Science Ltd
\end{abstract}

\section{Introduction}

The importance of knowing the anatomy of the vascular bed at the scale of thermally significant blood vessels (larger than $0.2 \mathrm{~mm}$ in diameter) was recognized [3, 4]. However, the Pennes [1] bio-heat transfer equation (PBHTE), based on the assumption that the blood enters the tissue at a fixed arterial temperature and leaves the tissue at the local tissue temperature, is widely used to solve the temperature distribution in living tissue for a given absorbed power deposition during thermal therapies. Also, the PBHTE is based on the assumption that all heat transfer between the tissue and the blood occurs in the capillaries. In other words, this continuum approach neglects the local effects that "thermally significant" 
blood vessels have interacted on the temperature/thermal dose fields inside the tissue.

The primary aim of this study is to examine the effect of thermally significant blood vessel by introducing the energy transport equation of the blood flow. Deng and Liu [5] studied analytical solution to the $b$ io-heat transfer p roblems w ith s patial or transient h eating on s kin s urface or i nside b iological bodies using Green's function method. Without considering the blood vessel effect, their solutions were applied to several selected typical bio-heat transfer processes, which are often encountered in cancer hyperthermia, laser surgery, and tissue thermal parameter estimation. Chato [6] investigated heat transfer to blood vessels in three configurations including a single vessel, two vessels in counterflow, and a single vessel near the skin surface. However the heating deposition power in tissue and the axial conduction in blood flow and tissue are not considered. Furthermore, Huang et al. [7] discussed the two cases (a) the average axially varying temperature of the blood and (b) the temperatures in its surrounding tissue, and obtained the analytical solutions. And their studies are restricted to a simple geometry and without considering the variation due to axially temperature gradient in tissue. There is little information concerning the effect of thermally significant large blood vessel on the temperature distribution and thermal lesion. Therefore, this study investigates the effects of thermally significant blood vessel with different diameters and velocities on thermal distributions within the heated tumor volume.

\section{Methods}

\section{$\underline{\text { Temperature Predications }}$}

The energy equations of tissue and blood are represented in equations (1) and (2), respectively. The model of angularly symmetric geometry was used in the simulation, as shown in Fig. 1. There is a blood vessel throughout the heated perfused tumor tissue. For the tissue domain, the transient Pennes bio-heat transfer equation in cylindrical coordinates is given in Equation (1). Perfusion is assumed uniform throughout the entire tissue volume, and the heat generation of metabolism of tissue is neglected. If the effect of pulsation of the blood circulation ( $w=$ constant) is ignored, the energy transport equation in the blood domain is used in Equation (2).

$$
\rho_{t} c_{t} \frac{\partial T}{\partial t}=k_{t}\left[\frac{1}{r} \frac{\partial}{\partial r}\left(r \frac{\partial T}{\partial r}\right)+\frac{\partial^{2} T}{\partial z^{2}}\right]-W_{b} c_{b}\left(T-T_{a}\right)+Q_{t}(r, z, t)
$$




$$
\rho_{b} c_{b}\left(\frac{\partial T}{\partial t}+w \frac{\partial T}{\partial z}\right)=k_{b}\left[\frac{1}{r} \frac{\partial}{\partial r}\left(r \frac{\partial T}{\partial r}\right)+\frac{\partial^{2} T}{\partial z^{2}}\right]+Q_{b}(r, z, t)
$$

Since the parameters, $\rho, c, k$, of tissue and blood are the same, as shown in Table 1, a simple dimensionless form can be formulated. The temperatures of initial and boundary conditions are all set to $37^{\circ} \mathrm{C}$. The dimensionless parameters are defined as

$$
\theta=\frac{T-T_{a}}{T_{a}}, \quad R=\frac{r}{r_{0}}, \quad Z=\frac{z}{r_{0}}, \tau=\frac{k_{t} t}{\rho_{t} c_{t} r_{0}^{2}}
$$

Equations (1) and (2) can express as the same form but with the different coefficients

$$
\frac{\partial \theta}{\partial \tau}+A_{1} \frac{\partial \theta}{\partial Z}=\frac{1}{R} \frac{\partial}{\partial R}\left(R \frac{\partial \theta}{\partial R}\right)+\frac{\partial^{2} \theta}{\partial Z^{2}}-A_{2} \theta+A_{3}
$$

where

$$
A_{1}=\frac{\rho_{t} c_{t} w r_{0}}{k_{t}} ; A_{2}=\frac{W_{b} c_{b} r_{0}^{2}}{k_{t}} ; A_{3}=\frac{r_{0}^{2} Q}{k_{t} T_{a}} .
$$

For the tissue domain, the coefficient $A_{1}$ equals zero. For the blood vessel domain, the coefficient $A_{2}$ becomes zero. Equation (4) can be expressed in terms of the explicit finite difference form as

$$
\theta_{i, j}^{n+1}=c_{1} \theta_{i, j}^{n}+c_{2} \theta_{i+1, j}^{n}+c_{3} \theta_{i-1, j}^{n}+c_{4} \theta_{i, j+1}^{n}+c_{5} \theta_{i, j-1}^{n}+c_{6}
$$

where

$$
\begin{aligned}
& c_{1}=1-c_{2}-c_{3}-c_{4}-c_{5}-A_{2} \Delta \tau \\
& c_{2}=\frac{\Delta \tau}{\left(\Delta Z_{i}\right)\left(\Delta Z_{i+1 / 2}\right)} ; \quad c_{3}=A_{1} \frac{\Delta \tau}{\Delta Z_{i}}+\frac{\Delta \tau}{\left(\Delta Z_{i}\right)\left(\Delta Z_{i-1 / 2}\right)} ; \quad c_{4}=\frac{\left(R_{j+1 / 2}\right) \Delta \tau}{\left(R_{j}\right)\left(\Delta R_{j}\right)\left(\Delta R_{j+1 / 2}\right)} \\
& c_{5}=\frac{\left(R_{j-1 / 2}\right) \Delta \tau}{\left(R_{j}\right)\left(\Delta R_{j}\right)\left(\Delta R_{j-1 / 2}\right)} ; \quad c_{6}=A_{3} \Delta \tau
\end{aligned}
$$




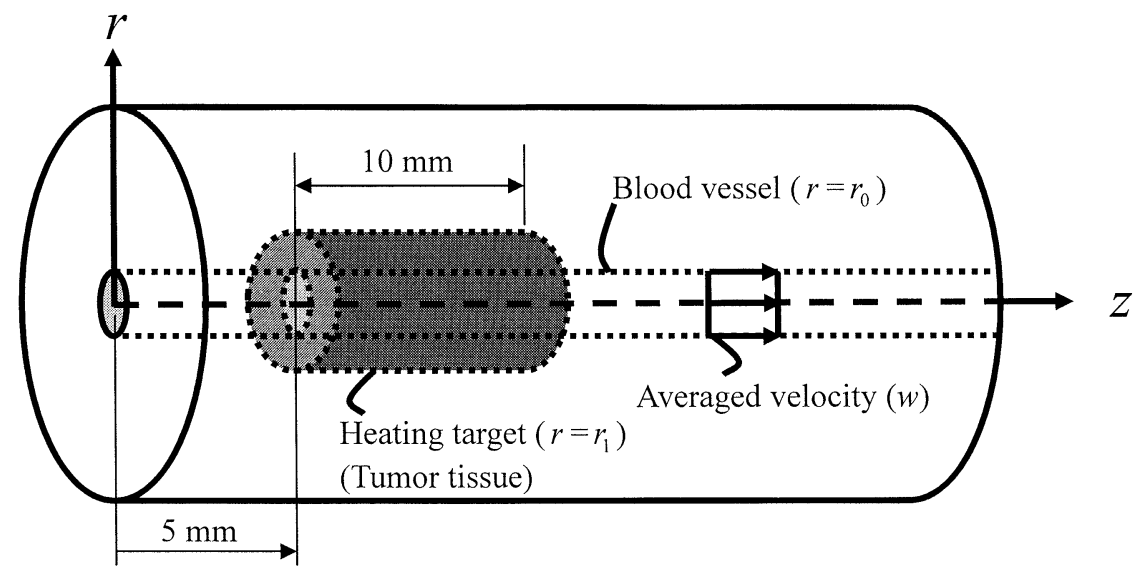

FIG. 1

The geometry for the simulation where heating target ( $5 \mathrm{~mm} \leqq z \leqq 15 \mathrm{~mm}, 0<r \leqq 5 \mathrm{~mm}$ ) and the uniform velocities in the blood vessels and their diameters are shown in Table 2.

TABLE 1

Parameters used for Simulation

\begin{tabular}{cccc}
\hline \hline Symbol & Definition & Value & Unit \\
\hline$\rho_{t}, \rho_{b}$ & Density of tissue and blood & 1050 & $\mathrm{~kg} / \mathrm{m}^{3}$ \\
$c_{t}, c_{b}$ & Specific heat of tissue and blood & 3770 & $\mathrm{~J} / \mathrm{kg}{ }^{\circ} \mathrm{C}$ \\
$r_{0}$ & Radius of blood vessel & $0.1 \sim 1$ & $\mathrm{~mm}$ \\
$r_{1}$ & Radius of tumor tissue (the heating target) & 5 & $\mathrm{~mm}$ \\
$k_{t}, k_{b}$ & Thermal conductivity of tissue and blood & 0.5 & $\mathrm{~W} / \mathrm{m}^{\circ} \mathrm{C}$ \\
$w$ & Averaged blood velocity & $3.4 \sim 20$ & $\mathrm{~mm} / \mathrm{s}$ \\
$W_{b}$ & Blood perfusion rate & 5 & $\mathrm{~kg} / \mathrm{m}^{3} \mathrm{~s}$ \\
$T_{a}$ & Arterial temperature & 37 & ${ }^{\circ} \mathrm{C}$ \\
$Q$ & Absorbed power density of tissue and blood & $6,0.6$ & $\mathrm{~W} / \mathrm{cm}^{3}$ \\
\hline \hline
\end{tabular}

Five different vessel diameters and blood velocities are used as shown in Table2. The blood flow in tumors is markedly different from those in normal tissues. In general, the blood perfusion in tumors is poorer than in the host's normal tissues. Herein the averaged blood velocity in tumor is assumed to be 0.1 times that in normal tissue [8]. Furthermore, the heat power is deposited by ultrasound so that the absorption rate of blood is about 1/10 comparing with the tissue [9]. During the simulation, the ultrasound power was uniformly deposited within the heating volume. Besides, the heating power density is $6 \mathrm{~W} / \mathrm{cm}^{3}$ for tissue, and the heating duration is 20 seconds. 
TABLE 2

Blood vessel characteristics of a $13-\mathrm{kg}$ dog in references $[4,6]$

\begin{tabular}{|c|c|c|c|}
\hline Case & $\begin{array}{c}\text { Diameter } \\
(\mathrm{mm})\end{array}$ & $\begin{array}{c}\text { Blood velocity in normal tissue } \\
(\mathrm{mm} / \mathrm{s})\end{array}$ & $\begin{array}{c}\text { Blood velocity in tumor }(w) \\
(\mathrm{mm} / \mathrm{s})\end{array}$ \\
\hline I & 0.2 & 34 & 3.4 \\
\hline II & 0.6 & 60 & 6 \\
\hline III & 1.0 & 80 & 8 \\
\hline IV & 1.4 & 105 & 20.5 \\
\hline V & 2.0 & 200 & \\
\hline
\end{tabular}

\section{Thermal Dose Calculations}

The deposited thermal dose induced by the heating treatment depends not only on the therapeutic temperature levels but also on the heating duration. The thermal dose or equivalent minutes at $43^{\circ} \mathrm{C}$ defined by Sapareto and Dewey [2] can describe the extent of thermal damage or destruction of tissue, and its expression is

$$
E M_{43}(\text { in } \min .)=\int R^{(T-43)} d t
$$

where $R=2$ for $T \geq 43^{\circ} \mathrm{C}, R=4$ for $37^{\circ} \mathrm{C}<T<43^{\circ} \mathrm{C}, T$ is temperature, and $t$ is time. The threshold dose for necrosis ranges from $E M_{43}=25$ to $240 \mathrm{~min}$ for brain and muscle tissue, respectively [2, 10]. In this simulation study, a conservative value $\left(E M_{43}=300 \mathrm{~min}\right)$ has been taken. Parameter values of simulations are shown in Table 1.

\section{$\underline{\text { Results and Discussion }}$}

On the $r-z$ plane, Figs. 2(a) to 2(d) illustrate that the temperature development increases during the heating duration and then Figs. 2(e) to 2(h) show that the temperature distributions decays after the heating power is turned off. It is found that the blood vessel has a significant heat exchange effect on the tissue, which introduces a higher temperature gradient near the blood vessel. Meanwhile, this effect also induces a pronounced temperature rise of the blood vessel itself along the downstream. 

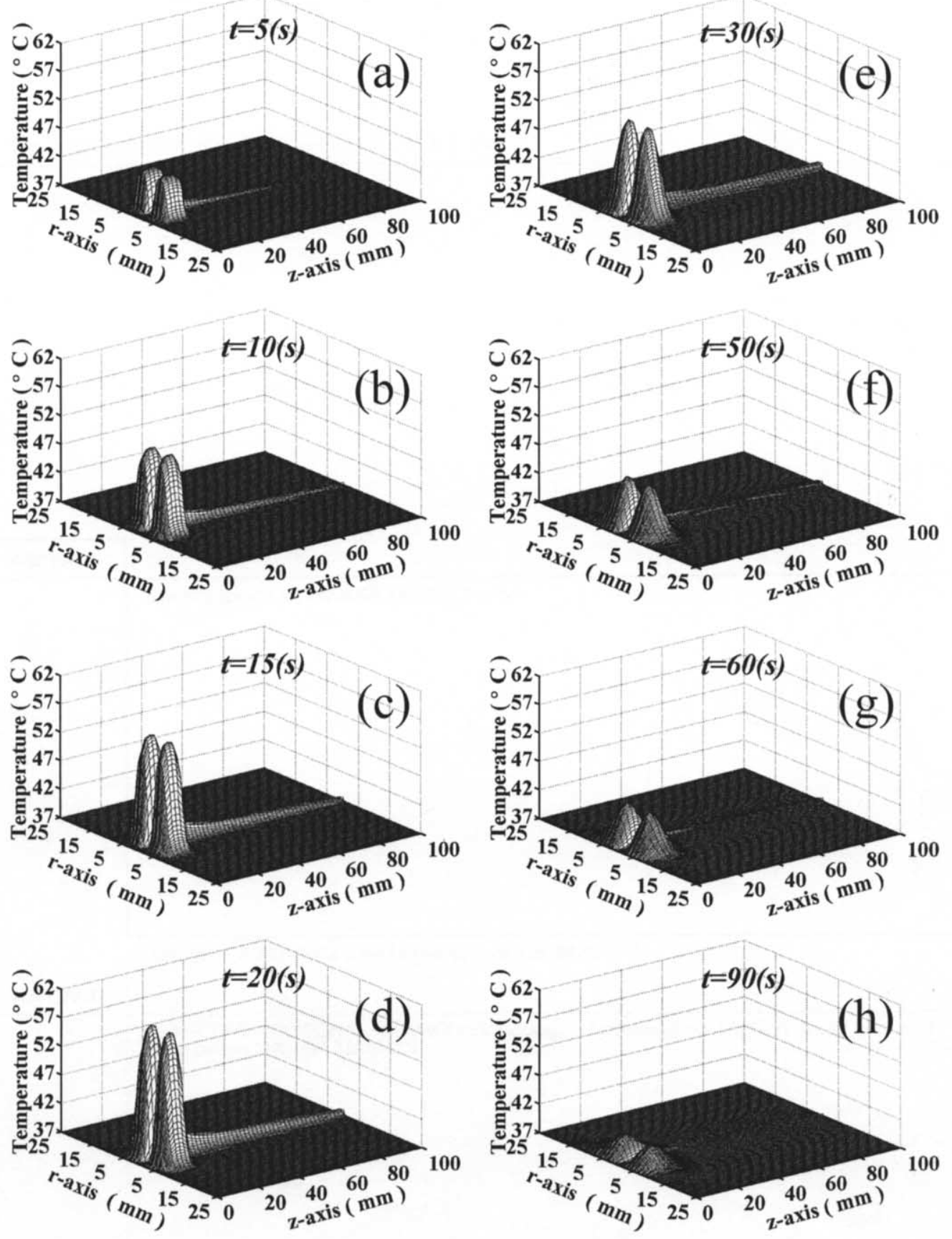

FIG. 2

The development of temperature distribution on the $r-z$ plane for time ranging from 5 to $90 \mathrm{~s}$ for the case $\mathrm{V}, W_{\mathrm{b}}=5 \mathrm{~kg} / \mathrm{m}^{3} \mathrm{~s}, k_{b}=k_{t}=0.5 \mathrm{~W} / \mathrm{m}^{\circ} \mathrm{C}$ when heating power is turned off at $t=20 \mathrm{~s}$. 
Figure 3 demonstrates the effects of thermally significant blood vessels with different diameters and averaged velocities on the thermal dose $\left(E M_{43}\right)$ profiles. The thermal dose profile in Fig. 3(a) displays the bell-shaped distribution and its peak is over $10^{6} \mathrm{~min}$. In the absence of the blood vessel, Figure 3(a) shows that the thermal cure effectively covers the wanted therapeutic region except the corners where the heat conduction effect diffuses its thermal dose. Figure 3(b) shows that the thermal dose inside the blood vessel still reaches the therapeutic level even with a single blood vessel (i.e., $0.2 \mathrm{~mm}$ in diameter and the averaged velocity $3.4 \mathrm{~mm} / \mathrm{s}$ ) passing throughout the heated tissue. In other words, when the diameter of blood vessels is less than $0.2 \mathrm{~mm}$, the cooling effect of the blood flow can be ignored. When the large blood vessel passes throughout the tumor tissue, Figs. 3(c) to 3(f) depict that the thermally significant blood vessel passing through the heated volume has the cooling effect on the heated region. This will cause the i neffective thermal dose level occurred near the blood vessel. With the increasing in blood vessel diameter, the thermal dose level in the center of blood vessel becomes lower and the gap between the two peaks of thermal dose also becomes larger. Therefore, it needs to develop an improved heating model to remedy this inherent drawback.

Figure 4 shows the thermal dose contours $E M_{43}=300$ min on the $r-z$ plane. Although the heating power is diffused from tissue to the blood vessel and the blood temperature is raised, as shown in Fig. 2, the temperature of heated tissue near the inlet of the blood vessel in hyperthermia region is still very low. Therefore, the region of tumor tissue near the inlet of the blood flow in hyperthermia region obviously is difficult to reach the therapeutic thermal dose level shown in Figs 4(b). When the diameter of blood vessel is less than $0.6 \mathrm{~mm}$ as shown in Fig. 4(c), however, the thermal lesion extends to normal tissue near the outlet of the blood flow in hyperthermia region. When the diameter of blood vessel is greater than $1.0 \mathrm{~mm}$ as shown in Figs. 4(d) to 4(f), the cooling effect of the blood flow has caused the thermal dose pattern into two separate small regions of thermal lesion on the r-z plane and hence produced inefficient therapeutic region.

\section{$\underline{\text { Conclusions }}$}

The presence of thermally significant blood vessels that flow from unheated regions of normal tissue into the heated tumor tissue $\mathrm{c}$ auses the pronounced cooling e ffect on the region inside the heated tumor tissue. When the diameter of blood vessel is larger than $0.2 \mathrm{~mm}$, the thermally significant blood vessels result in the cooling of the region near the inlet of the heated tumor tissue. Besides, the region near the outlet of blood flow in hyperthermia region has been overheated while the vessel diameter is less than $0.6 \mathrm{~mm}$. When the diameter of blood vessel is greater than $1.0 \mathrm{~mm}$, the cooling effect of the blood flow has caused the thermal dose pattern into two separate small regions of thermal lesion and hence produced inefficient therapeutic region. 

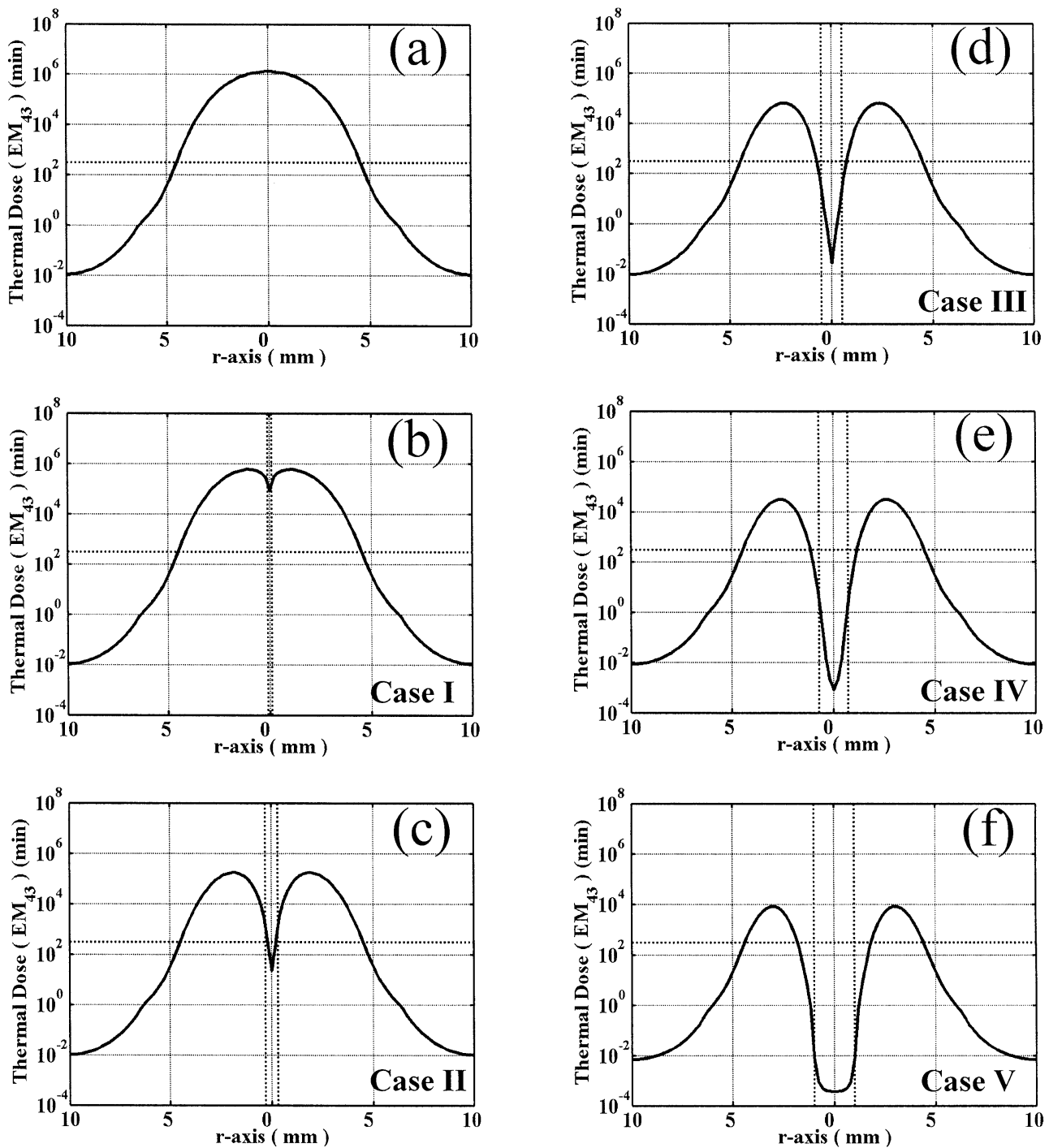

FIG. 3

Thermal dose profiles on the cross sections located at $z=10 \mathrm{~mm}$ and $t=90 \mathrm{~s}$ for $W_{b}=5 . \mathrm{kg} / \mathrm{m}^{3} \mathrm{~s}$, the averaged blood velocities $w$ ranging from 0.34 to $2 \mathrm{~mm} / \mathrm{s}$, (a) in the absence of the blood vessel; (b)-(f) for cases I $\sim \mathrm{V}$. Note that the heating boundaries are $0<r \leqq 5 \mathrm{~mm}$. Vertical dashed lines represent the blood vessel boundaries from case I to case V in Table 2. Horizontal dashed lines are denoted with the thermal dose $E M_{43}=300 \mathrm{~min}$. 

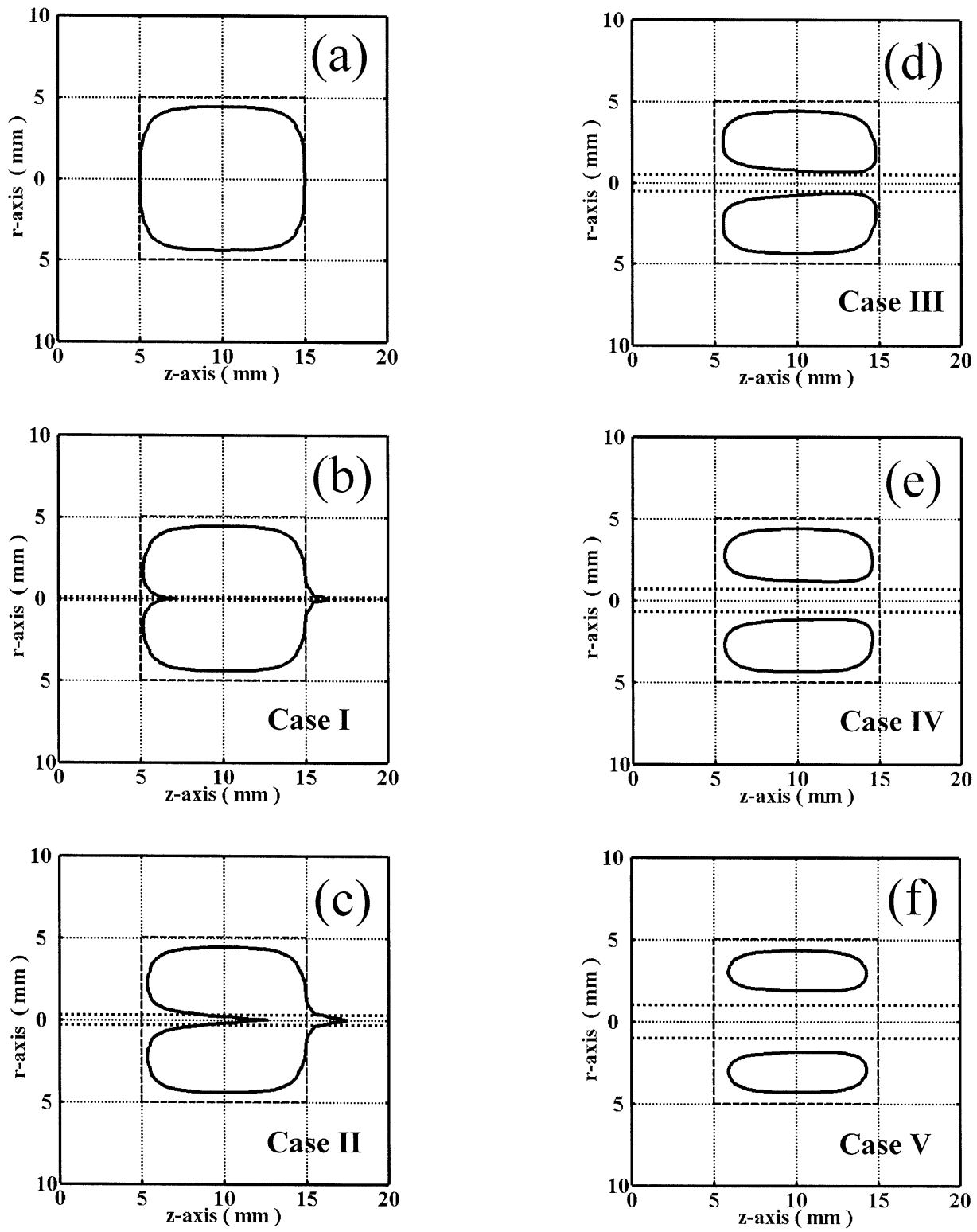

FIG. 4

Effects of the absence of a blood vessel and the five different blood vessels with the thermal dose contours $E M_{43}=300 \mathrm{~min}$ at $t=90 \mathrm{~s}$. The blood vessels boundaries are denoted with the horizontal dashed lines. The heated target regions are denoted with the square-shaped dashed lines. 


\section{$\underline{\text { Nomenclature }}$}

$c$ specific heat $\left(\mathrm{J} / \mathrm{kg}{ }^{\circ} \mathrm{C}\right)$

$k$ thermal conductivity $\left(\mathrm{W} / \mathrm{m}{ }^{\circ} \mathrm{C}\right)$

$Q$ absorbed power deposition density $\left(\mathrm{W} / \mathrm{cm}^{3}\right)$

$r$ distance along $\mathrm{r}$-axis $(\mathrm{mm})$

$r_{0}$ radius of the blood vessel $(\mathrm{mm})$

$r_{1}$ radius of the heating tumor tissue $(\mathrm{mm})$

$R$ dimensionless radius, $R=r / r_{0}$

$t$ time (s)

$T$ temperature $\left({ }^{\circ} \mathrm{C}\right)$

$T_{a}$ arterial temperature $=37\left({ }^{\circ} \mathrm{C}\right)$

$w$ averaged blood velocity along z-direction $(\mathrm{mm} / \mathrm{s})$

$W_{b}$ blood perfusion rate $\left(\mathrm{kg} / \mathrm{m}^{3} \mathrm{~s}\right)$

$z$ distance along $\mathrm{z}$-axis $(\mathrm{mm})$

$Z$ dimensionless distance, $Z=z / r_{0}$

$\theta$ dimensionless temperature, $\theta=\frac{T-T_{a}}{T_{a}}$

$\rho$ density $\left(\mathrm{kg} / \mathrm{m}^{3}\right)$

$\tau$ dimensionless time, $\quad \tau=\frac{k_{t} t}{\rho_{t} c_{t} r_{0}^{2}}$

\section{$\underline{\text { Subscripts }}$}

$b$ blood

$t$ tissue

\section{$\underline{\text { References }}$}

1. H. H. Pennes, J. Appl. Physiol. 1, 93 (1948).

2. S. A. Sapareto, and W. Dewey, Int. J. Radiat. Oncol. Biol. Phys. 10, 787 (1984).

3. J. Crezee and J. J. W. Lagendijk, Phy. Med. Biol., 35, 905 (1990).

4. M. C. Kolios, M. D. Sherar, and J. W. Hunt, Med. Phys. 23, 1287 (1996). 
5. Z. S. Deng, and J. Liu, ASME J. Biomech. Eng. 124, 638 (2002).

6. J. C. Chato, ASME J. Biomech. Eng. 102, 110 (1980).

7. H. W. Huang, C.L. Chan, and R. B. Roemer, ASME J. Biomech. Eng. 116, 208 (1994).

8. C. W. Song, I. B. Choi, B. S. Nah, S. K. Sahu, and J. L. Osborn, Thermoradiotherapy and Thermochemotherapy, vol. 1: Biology, Physics, Physics, p. 139, Springer-Verlag, Berlin Heidelberg (1995).

9. F. A. Duck, Physical Properties of Tissues: A Comprehensive Reference Book, Academic Press, San Diego (1990).

10. C. Damianou, and K. Hynynen, Ultrasound Med. Biol. 19, 777 (1993).

Received March 24, 2003 